\title{
PENGARUH STIMULASI PERMAINAN ULAR TANGGA TENTANG GINGIVITIS TERHADAP PENGETAHUAN ANAK USIA 8-11 TAHUN Studi terhadapSiswa SD Negeri Kuningan 04, Kecamatan Semarang Utara
}

\author{
Syarifah Nur Laili Siyam*, Arlina Nurhapsari**, Benni Benyamin**
}

\section{ABSTRACT}

Keywords:

snakes and ladders

game, knowledge

gingivitis, children ages 8-11 years

Background: Health education was an attempt to increase the knowledge of children to health problems. The provision of health education can be done through stimulation using Educational Educative Equipment (APE) form snakes and ladders game. One of the health problems that was unfamiliar to the child that is gingivitis. Purpose: This study was conducted to determine the effect of stimulation of gingivitis snakes and ladders game against the knowledge of children ages 8-11 years. Method: This research method using descriptive analytic with pre and post test design. Samples were collected using simple random sampling method comprising 102 respondents based on inclusion criteria of the SD N Kuningan 04. The independent variable is the stimulation of snakes and ladders game. The dependent variable is the child's knowledge about gingivitis. Data were collected using a questionnaire and analyzed the Wilcoxon Signed Rank test. Result: Based on the Wilcoxon Signed Rank test showed significance value $0.00(p<0.05)$, so it can be concluded that health education using stimulation of snakes and ladders game has the effect to increase the knowledge of gingivitis in children. Conclusion: From these results it can be concluded that education using the stimulation of snakes and ladders game effect to increase children's knowledge about gingivitis.

\section{PENDAHULUAN}

Penyakit periodontal merupakan penyakit inflamatorik pada jaringan penunjang gigi geligi dikarenakan aktivitas bakteri. Penyakit periodontal terdiri atas gingivitis dan periodontitis 1.Gingivitis merupakan tahap pertama dalam perkembangan penyakit periodontal yang paling sering dijumpai baik pada usia muda maupun dewasa, dimana terjadi inflamasi yang meliputi jaringan gingiva disekitar gigi sebagai rerspon terhadap bakteri dan plak yang akan berlanjut dengan terbentuknya poket periodontal ${ }^{2}$. Prevalensi gingivitis di Indonesia menduduki urutan kedua yaitu mencapai $96,58 \%$. Berdasarkan Riset Kesehatan Dasar (RISKESDAS) pada tahun 2007, masalah gigi dan mulut termasuk penyakit pada gingiva di Provinsi Jawa Tengah yaitu sebesar $25,8 \%{ }^{3}$.

Gingivitis merefleksikan keberadaan kesehatan mulut yang kurang baik karena gingivitis terjadi oleh adanya akumulasi plak disekitar gigi dan gusi akibat kurangnya kesadaran untuk menyikat gigi secara teratur ${ }^{4}$. Faktor perilaku mengabaikan kebersihan gigi dan mulut merupakan salah satu penyebab timbulnya gingivitis. Hal tersebut disebabkan kurangnya pengetahuan akan pentingnya pemeliharaan kesehatan gigi dan mulut ${ }^{5}$.

Upaya peningkatan pengetahuan dan sikap anak terhadap permasalahan kesehatan dapat berupa stimulus melalui permainan. Jenis permainan yang dapat digunakan salah satunya adalah permainan ular tangga 6 . Permainan ular tangga merupakan suatu permainanyang sejalan dengan perkembangan kognitif anak usia 8-11 tahun, dimana anak

*Program Pendidikan Dokter Gigi Fakultas Kedokteran Gigi Unissula Semarang, ** Staff Pengajar Fakultas Kedokteran Gigi Universitas Islam Sultan Agung Semarang

Korespondensi : syarifahnuralatas@gmail.com 
usia tersebut mulai dapat menerima suatu permainan yang banyak diwarnai dengan nalar dan logika yang bersifat obyektif serta kegiatan anak dalam bermain lebih banyak dikendalikan oleh aturan yang ada dalam permainan ${ }^{7}$.

Berdasarkan uraian diatas, penulis tertarik membuat permainan ular tangga untuk dijadikan sebagai media pendidikan kesehatan kepada anak yang telah disesuaikan dengan tema penyuluhan yaitu gingivitis. Hasil penelitian ini diharapkan dapat memberikan sumbangan bagi kedokteran gigi dan memperkaya hasil penelitian yang telah ada dan dapat memberi gambaran mengenai pengaruh stimulasi permainan ular tanggatentang gingivitis terhadap pengetahuan anak usia 8-11 tahun.

\section{METODE PENELITIAN}

Jenis penelitian yang digunakan adalah penelitian analisis deskriptif dengan pre and post test design. Sampel diambil dengan menggunakan teknik simple random sampling. Sampel didapatkan sebanyak 102 anak.

Instrumen yang digunakan dalam penelitian ini adalah kuesioner pre and post test yang telah diuji validitasnya dan permainan ular tangga sebagai media penyuluhan gingivitis.

\section{Tahap penelitian:}

Sampel diambil menggunakan teknik simple random sampling. Jumlah responden yang akan diteliti adalah 102 anak. Peneliti menjelaskan terlebih dahulu cara pengisian kuesioner kepada responden. Peneliti mendampingi responden saat pengisian kuesioner pre test. Peneliti membagi siswa menjadi kelompok-kelompok kecil untuk memainkan permainan ular tangga modifikasi. Setiap kelompok berisi minimal 2 orang anak dan maksimal 4 orang anak. Permainan dimainkan satu kali putaran. Permainan ular tangga selesai, responden mengisi kuesioner post test. Peneliti mendampingi, mengambil hasil post test

Analisis deskriptif untuk mengetahui perubahan rata-rata pengetahuan pre and post test responden. Apabila hasil uji normalitas data berdistribusi normal, menggunakan analisis parametrik pada 2 kelompok berpasangan dengan uji Paired t-test untuk membandingkan hasil pre and post test. Uji alternatif apabila data tidak berdistribusi normal menggunakan analisis non parametrik dengan uji Wilcoxon test.

Tabel 1 Rata-Rata Pengetahuan Pre and Post Test

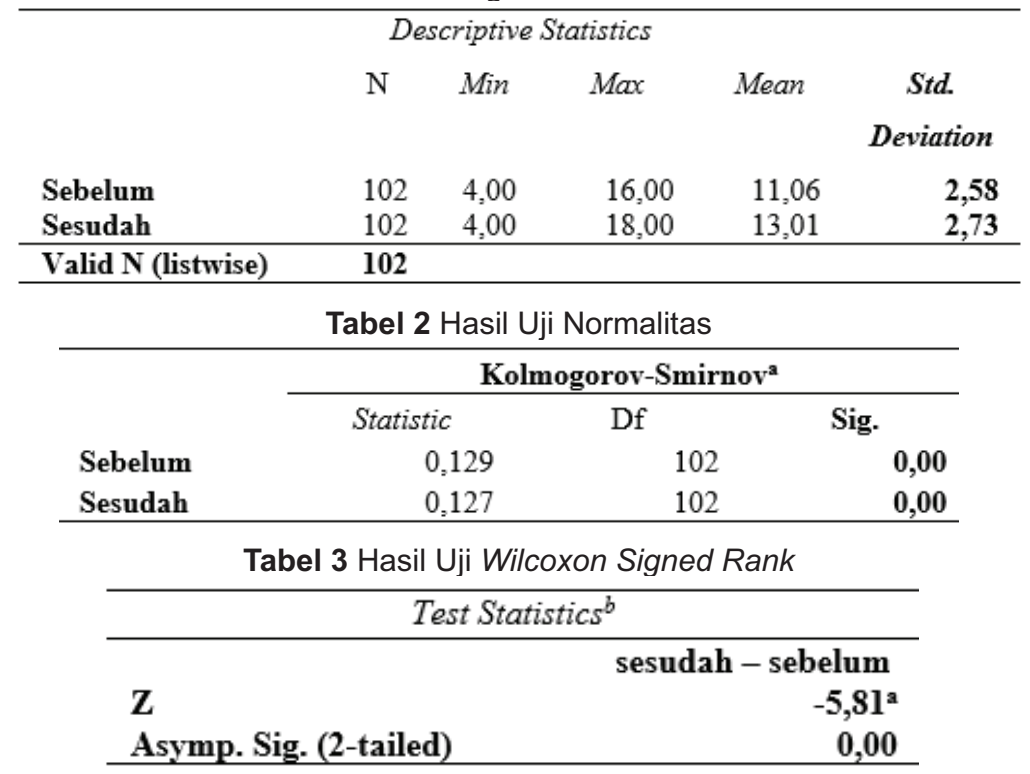




\section{HASIL PENELITIAN}

Hasil uji normalitas dari tabel 2 menggunakan Kolmogorov - Smirnov mendapatkan nilai signifikansi kurang dari level of significance 0,05 masing-masing sebesar 0,00 untuk hasil pre and post test. Kedua data tidak berdistribusi normal sehingga uji yang digunakan adalah uji non parametrik yaitu Wilcoxon Signed Rank untuk mengetahui kebermaknaan perbedaan pengetahuan pre and post test.

Pada Tabel 3 menunjukkan hasil statistik dari pre and post test mendapatkan nilai -5,81a dengan asymp.sig sebesar 0,00. Nilai signifikansi yang lebih kecil dari level of significance 0,05 menunjukkan bahwa Ho ditolak dan Ha diterima. Hal ini berarti menerima hipotesis yang menyatakan bahwa terdapat pengaruh penyuluhan menggunakan stimulasi permainan ular tangga tentang gingivitis terhadap peningkatan pengetahuan anak usia 8-11 tahun.

\section{DISKUSI}

Penelitian dilakukan untuk mengetahui pengaruh stimulasi permainan ular tangga tentang gingivitis pada anak usia 8-11 tahun yang dilakukan terhadap siswa SD Negeri Kuningan 04, Kecamatan Semarang Utara.

Berbagai manfaat permainan ular tangga diantaranya merupakan suatu permainan yang menarik, menyenangkan untuk dilakukan, dan dapat meningkatkan kemampuan sosialisasi anak dengan teman sebayanya. Hal ini nampak dari antusias anak dalam berkompetisi dengan teman bermainnya untuk menyelesaikan permainan. Permainan ular tangga ini sesuai untuk usia anak 8-11 tahun sebagaimana teori yang dikemukakan oleh Piaget bahwa dalam permainan ini melibatkan banyakanak dalam kegiatan bermain yang diwarnai dengan berbagai aturan permainan, penalaran, dan logika yang bersifat obyektif 7 .

Pengetahuan pre test and post test responden terlihat dari peningkatan rata-rata pengetahuansetelah diberi intervensi berupa permainan ular tangga yaitu pre test sebesar 11,06 dan post test sebesar 13,01. Dari hasil tersebut sesuai dengan teori Notoatmodjotahun 2007 yang mengungkapkan bahwa pendidikan mempengaruhi pengetahuan seseorang 8 . Diharapkan dengan penanaman pengetahuan melalui pendidikan kesehatan yang didesain dengan baik tersebut dapat membentuk sikap anak yang mempengaruhi perilaku pada anak dalam menjaga kesehatan gusinya 9 . Terjadinya peningkatan pengetahuan anak setelah diberi intervensi merupakan penanaman pengetahuan yang sesuai dengan salah satu tujuan penyuluhan kesehatan.

Hasil perhitungan uji Wilcoxon Signed Rank menunjukkan nilai signifikansi 0,00 ( $p<$ $0,05)$. Berdasarkan hasil tersebut, pemberian penyuluhan sebagai pendidikan kesehatan menggunakan Alat Pendidikan Edukatif (APE) permainan ular tangga mengenai gingivitis, memiliki pengaruh terhadap peningkatan pengetahuan anak. Dalam penerapannya, setelah seseorang mengetahui stimulus atau objek yang diberikan, kemudian mengadakan penilaian atau pendapat terhadap apa yang telah diketahuinya, diharapkan pada proses selanjutnya anak akan mampu melakukan atau mempraktikkan apa yang diketahuinya ${ }^{10}$.

Penelitian ini sejalan dengan penelitian yang dilakukan oleh Nugrahani tahun 2007, terlihat dari antusiasme siswa saat menggunakan media pembelajaran berupa permainan ular tangga sangat baik11. Penelitian Hamdalah tahun 2013 dengan menggunakan media permainan ular tangga yang sejalan pula dengan penelitian ini, dapat disimpulkan bahwa permainan ular tangga lebih efektif dalam upaya meningkatkan pengetahuan, sikap, dan praktik terhadap kesehatan gigi dan mulut serta penerapan cara menggosok gigi dengan baik dan benar ${ }^{12}$.

Dalam penyampaian materi diperlukan pengarahan cara bermain dengan lebih memotivasi anak dan pemberian reward yang menarik agar anak lebih antusias lagi untuk memahami materi yang diberikan. Permainan ular tangga dibuat dengan modifikasi sedemikian rupa sebagai stimulus yang bertujuan meningkatkan motivasi anak agar 
lebih menyerap pengetahuan tentang gingivitis yang didapat dari proses permainan tersebut.

\section{KESIMPULAN}

1. Terdapat pengaruh stimulasi permainan ular tangga tentang gingivitis terhadap pengetahuan anak usia 8-11 tahun.

2. Terdapat perubahan rata-rata pengetahuan anak tentang gingivitis pada usia 8-11 tahun sebelum dan sesudah diberikan penyuluhan menggunakan stimulasi permainan ular tangga.

\section{DAFTAR PUSTAKA}

1. Wangsarahardja, K. Penyakit Periodontal sebagai Faktor Risiko Penyakit Jantung Coroner. Fakultas Kedokteran Universitas Trisakti. Journal Universa Medicina Vol.24 No.3 (2005).

2. Adiningrat, A., Hendrawati., Pramestri, S. Perbedaan antara Penggunaan Pasta Gigi yang Mengandung Propolis dan Tanpa Propolis terhadap Status Kesehatan Gingiva. Majalah IImu Kedokteran Gigi, 10(1): 17-9 (2008).

3. Riset Kesehatan Dasar (RISKESDAS). Laporan Nasional. Departemen Kesehatan Republik Indonesia; 2008. p. 130-2; Available from URL: http:www.scribd. com/doc/82922543/laporan Nasional-Riskesdas (2007).

4. Carranza, F.A. Clinical Periodontology (9th ed). Philadelphia: W.B. Saunders, p: 269- 77, 651-70 (2002).
5. Frankari. Pengaruh Penyuluhan dengan Metode Stimulasi dan Demonstrasi terhadap Perilaku Menjaga Kesehatan Gigi dan Mulut Anak Usia Sekolah Dasar. KaryaTulis IImiah. UGM (2004).

6. Augustyn, F. Dictionary of Toys and Games in American Popular Culture (2004).

7. Tedjasaputra, S., Mayke. Bermain, Mainan, dan Permainan. Jakarta: Grasindo (2001).

8. Notoadmodjo, S. Promosi Kesehatan dan IImu Perilaku. Jakarta: PT. Rineka Cipta (2007).

9. Dewi, A., Summi, A., Erwin, N. Peningkatan Pengetahuan Gizi Anak Usia Sekolah Melalui Pengoptimalan Pendidikan Jasmani dan Kesehatan Menggunakan Media Ular Tangga. Skripsi. Institut Pertanian Bogor (2011).

10. Notoatmodjo, S. Pendidikan dan Perilaku Kesehatan. Jakarta: PT. Rineka Cipta (2003).

11. Nugrahani, Rahina. Media Pembelajaran Berbasis Visual Berbentuk Permainan Ular Tangga Untuk Meningkatkan Kualitas Belajar Mengajar Di Sekolah Dasar. Lembaran IImu Kependidikan. Jilid 36, No. 1 (2007).

12. Hamdalah, A. Efektifitas Media Cerita Bergambar dan Ular Tangga dalam Pendidikan Kesehatan Gigi dan Mulut Siswa SDN 2Patrang Kabupaten Jember. Fakultas Kesehatan Masyarakat Universitas Jember. Jurnal Promkes Vol. 1, No. 2 Desember 2013: 118123 (2013). 